\title{
The Effect of Ozone Therapy on Experimental Vasospasm in the Rat Femoral Artery
}

\author{
Metin ORAKDOGEN ${ }^{1}$, Serap USLU², Selin TURAL EMON , Hakan SOMAY ${ }^{1}$, Zeynep CINGU MERIC ${ }^{3}$, \\ Tayfun HAKAN ${ }^{4}$ \\ ${ }^{1}$ Haydarpasa Numune Teaching and Research Hospital, Department of Neurosurgery, Istanbul, Turkey \\ ${ }^{2}$ Acibadem University, Vocational School of Health Services, Department of Histology and Embryology, Istanbul, Turkey \\ ${ }^{3}$ Atasehir Ozone Center, Istanbul, Turkey \\ ${ }^{4}$ Private Practice, Neurosurgeon, Istanbul, Turkey
}

\section{ABSTRACT}

AIM: Oxidation products following subarachnoid hemorrhage (SAH) are among the causative substances of cerebral vasospasm and poor outcome. Ozone $\left(\mathrm{O}_{3}\right)$ is a gas that contains three atoms of oxygen with a cyclic structure. It has been suggested that application of low-dose ozone has an antioxidant effect and provides resistance to oxidative stress. We investigated the effect of oxygen-ozone therapy on rat femoral artery vasospasm.

MATERIAL and METHODS: Twenty-four male Sprague-Dawley rats were randomly separated into vasospasm, vasospasm + ozone and control groups. The femoral artery vasospasm model was used. Rats in the vasospasm + ozone group were given $4 \mathrm{~mL}$ of ozone $(20 \mu / \mathrm{mL})$ daily for 7 days. Femoral arteries were examined by light microscopy for histological changes and morphometric analysis. Kruskal Wallis test and Mann Whitney $U$ tests were used for the statistical analysis. The values of $p<0.01$ and $p<0.05$ were recognized as statistically significant.

RESULTS: Ozone treatment reduced the morphometric changes as irregularity of the elastic lamina, disruption of the endothelial cells, vacuolization and hemorrhages that caused by vasospasm. The measurements of the wall thickness $(p=0.003 ; p<0.01)$ and lumen diameter $(p=0.001 ; p<0.01)$ showed statistically significant difference $(p<0.01)$ between the vasospasm and vasospasm+ozone groups.

CONCLUSION: Ozone therapy may be useful in the treatment of post-hemorrhagic vasospasm.

KEYWORDS: Cerebral vasospasm, Ozone, Ozone therapy, Rat femoral artery, Subarachnoid hemorrhage, Vasospasm

\section{INTRODUCTION}

$\longrightarrow$ erebral vasospasm is one of the main causes of poor prognosis after subarachnoid hemorrhage (SAH) (17). While the search for the treatment of post hemorrhagic cerebral vasospasm continues, the underlying mechanisms still rema-ins obscure (1). Oxidation products such as glutathione peroxidase (24) and lipid peroxides $(16,20)$, and inflammation $(1,14)$ following $\mathrm{SAH}$ are among the causative substances of cerebral vasospasm and poor outcome $(16,29)$.
Ozone $\left(\mathrm{O}_{3}\right)$ is a gas that contains three atoms of oxygen with a cyclic structure (5). It induces antioxidant stress and promotes resistance against oxidative stress $(13,15)$ and has been used as an antioxidant agent in inflammation (26). Oxygen-ozone therapy is known to be a bio-oxidative procedure (2) and application of low-dose ozone inhibits prostaglandin synthesis, release of bradykinin and algogenic substances, and proteinase secretion from macrophages and polymorphonuclear leukocytes (8). 
We report an experimental study to investigate the effect of oxygen-ozone therapy on rat femoral artery vasospasm.

\section{MATERIAL and METHODS}

The experimental protocol was approved by the Animal Care and Use Committee at Marmara University, School of Medicine. Twenty-four male Sprague-Dawley rats weighing approximately 250-300 g were housed with one animal per cage at the animal the Experimental Animal Implementation and Research Center (DEHAMER) of Marmara University.

Rats were separated randomly into three experimental groups, with eight rats in each: control, vasospasm, and vasospasm + ozone groups. The animals were anaesthetized by an intraperitoneal injection of ketamine $(100 \mathrm{mg} / \mathrm{kg})$ and allowed spontaneous breathing. The femoral artery vasospasm model described by Okada et al. (23) was used. A 10-mm segment of both femoral arteries were exposed by using a microsurgical technique in the inguinal region, $0.1 \mathrm{~mL}$ of fresh autologous whole blood derived from ventral tail artery was applied directly to the femoral artery and covered with a cylindrical silastic cuff. In vasospasm group each rat received a daily 4 $\mathrm{mL}$ of medical air that was insufflated rectally during 1 minute via an $18 \mathrm{G}$ cannula for 7 days. Rats in the vasospasm+ozone group each rat received a daily $4 \mathrm{~mL}$ of ozone $(20 \mu /$ $\mathrm{mL}$ ) (Medozon compact, Herrmann Apparatebau $\mathrm{GmbH}$, Germany) that was insufflated for 7 days. At the end of the 7 days all animals were anaesthetized as previously described and sacrificed. Femoral arteries were dissected and fixed in $10 \%$ formalin solution for 24 hours before tissue processing. Following paraffin embedding, tissue sections of $5-\mu \mathrm{m}$ were stained with hematoxylin-eosin (H\&E) for histomorphometric analyses and elastic Van Gieson (EVG) for evaluated internal elastic lamina. Histomorphometry was performed after the images were transferred from a light microscope (Zeiss Axio VertA1) via camera (AxioCamlCc 5 camera) into a computer. Lumen diameter and wall thickness of femoral arteries were measured by a semi-automatic digitizer The University of Texas Health Science Center At Santorini (UTHSCSA Image Tool for Windows Version 1.28). The samples from the femoral arteries were measured in 4 different points.

NCSS (Number Cruncher Statistical System) 2007 and PASS (Power Analysis and Sample Size) 2008 Statistical Software (Utah, USA) programs with the Kruskal-Wallis and MannWhitney $U$ tests were used for the statistical analysis. The values of $p<0.01$ and $p<0.05$ were recognized as statistically significant.

\section{RESULTS}

\section{Histological Changes}

Thin and smooth endothelium, unfolded internal elastic lamina and concentric smooth muscle cells were found and the lumen was clearly observed in control group (Figure 1A, B).

In the vasospasm alone group, disruption and proliferation of the endothelial cells into the lumen were observed. The internal elastic lamina was irregular. Vacuolization and hemorrhages into the tunica media were identified and concentric smooth muscle cells were seen to be irregular (Figure 2A, B).

The ozone group's endothelial cells had less disruption than the vasospasm group. Normal internal elastic lamina was shown. There was no hemorrhage or vacuolization in the tunica media (Figure 3A, B).
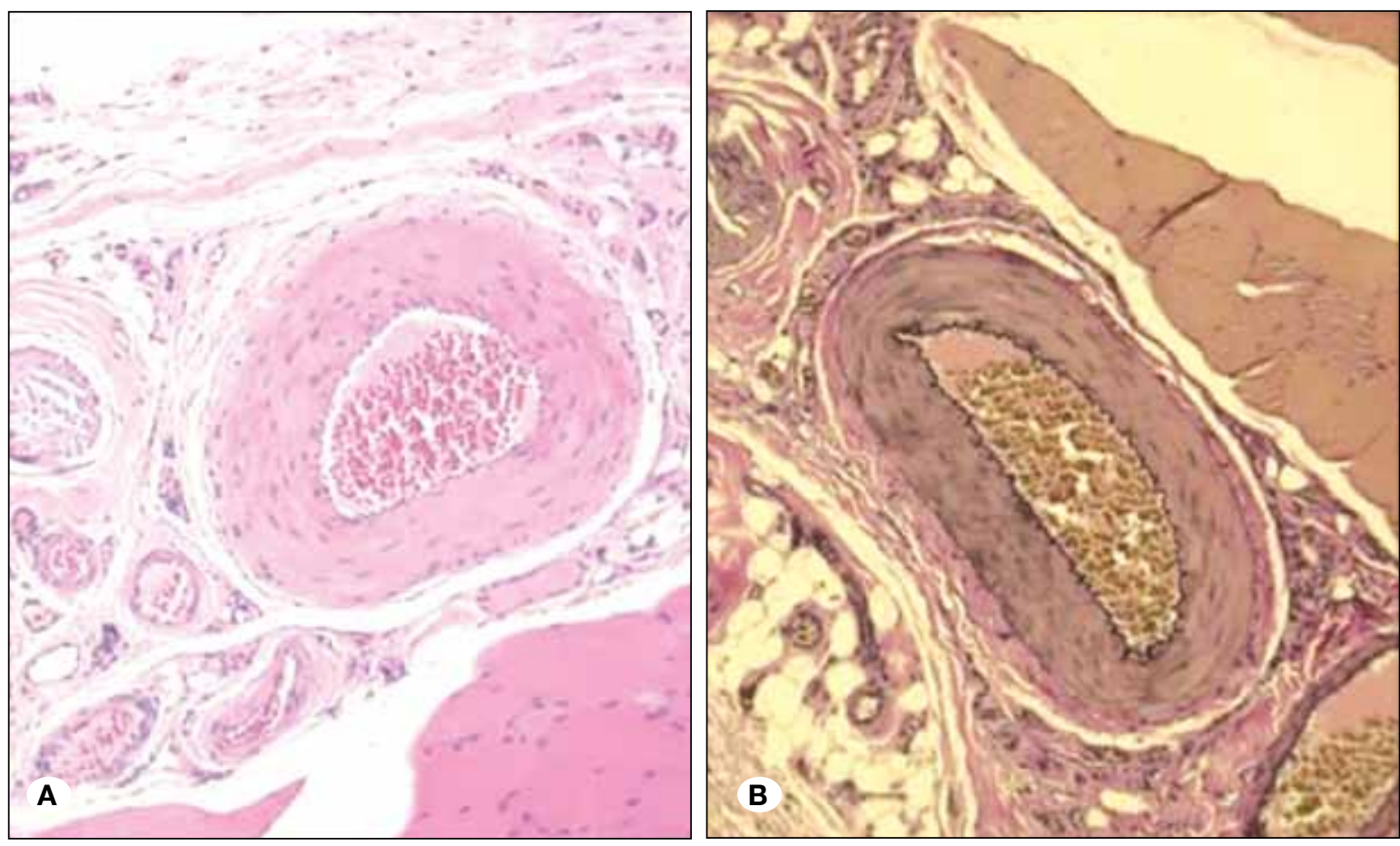

Figure 1:

Control group:

Uniform and regular endothelium,

A) H\&E, 200x

B) EVG, 200x. 


\section{Morphometric Analysis}

We compared the wall thickness and lumen diameters in all groups and summarized them as mean and standard deviation (Table I). The mean wall thickness was found to be $300.90 \pm 40.17,384.41 \pm 49.13$ and $289.23 \pm 65.98$ in the control, vasospasm and vasospasm+ozone groups respectively (Figure 4). The difference between the groups was statistically significant $(p=0.003 ; p<0.01)$. According to pair-wise comparison, the mean wall thickness of the vasospasm group was significantly more than the control and vasospasm+ozone groups $(p=0.009 ; p=0.002 ; p<0.01)$. There was no significant difference between mean wall thickness of control and vasospasm+ozone groups $(p=0.600 ; p>0.05)$.

The mean lumen diameter was $377.51 \pm 91.73,106.79 \pm 9.69$ and $182.59 \pm 58.48$ in the control, vasospasm and vasospasm+ ozone groups respectively (Figure 5 ). The difference between the groups was statically significant $(p=0.001 ; p<0.01)$. According to pair-wise comparison, the mean lumen diameter of the vasospasm group was significantly lower than the control and vasospasm+ozone groups $(p=0.006 ; p=0.001 ; p<0.01)$.
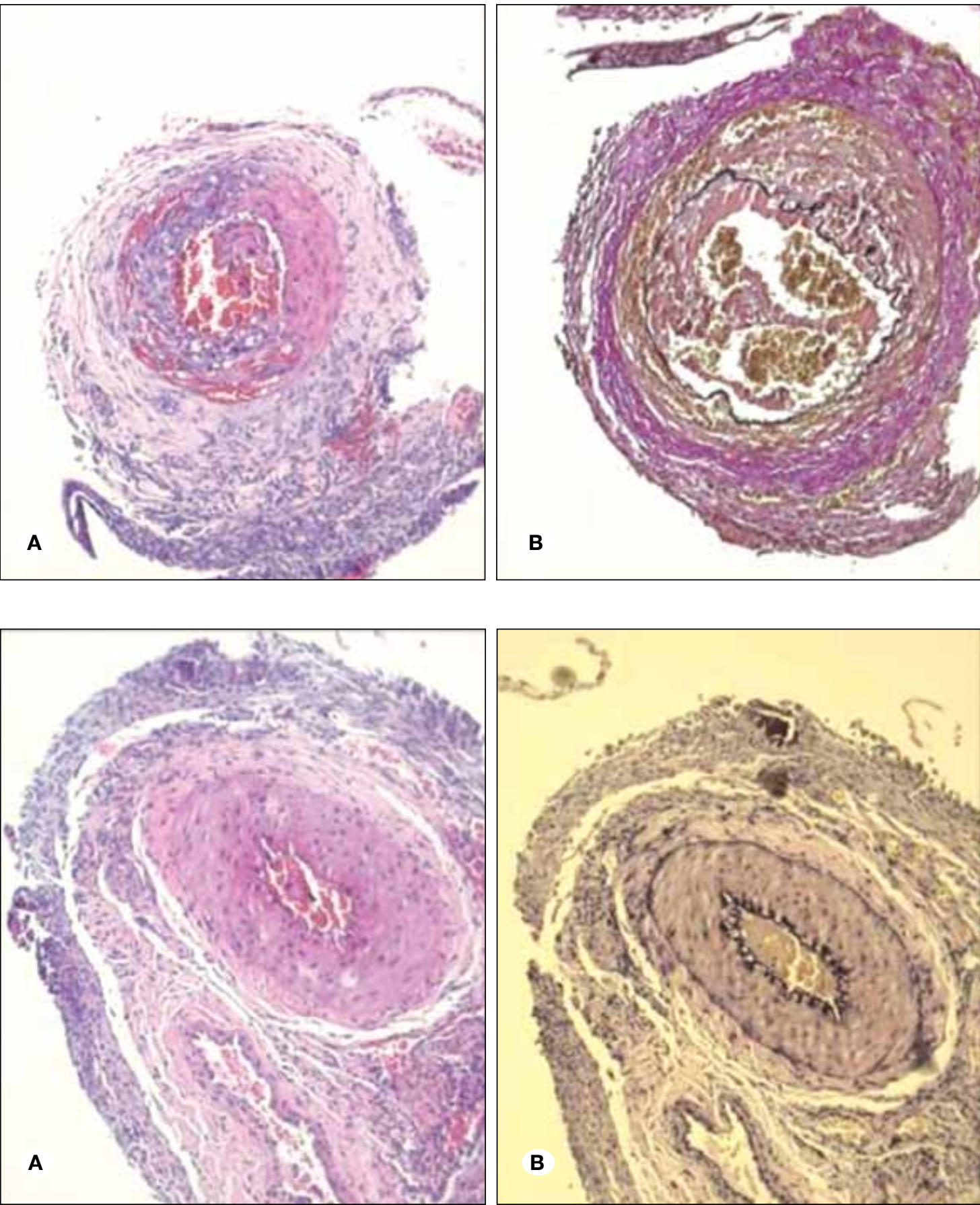

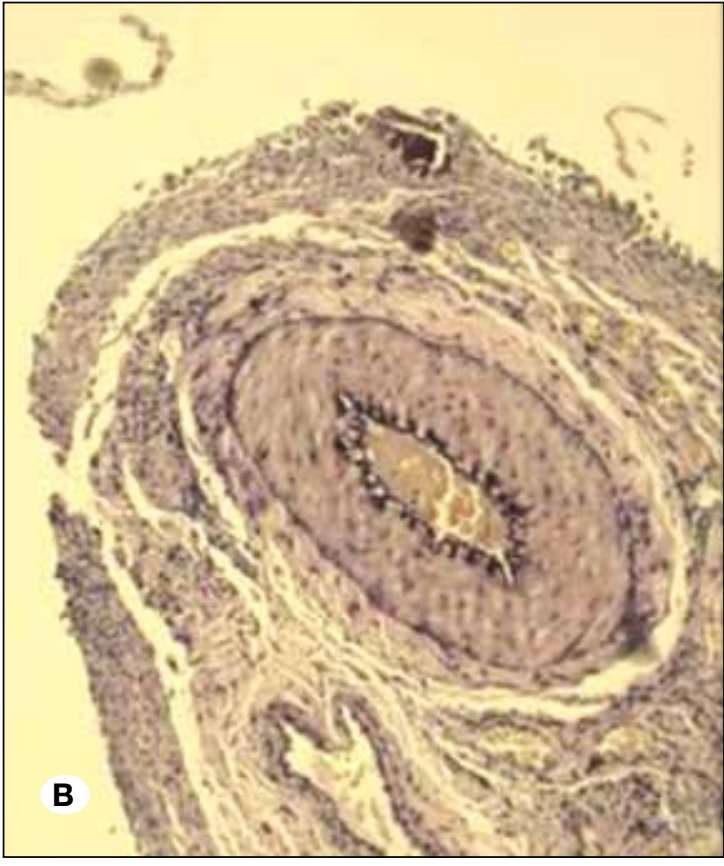

Figure 2: Vasospasm group: increased wall thickness and degenerated endothelium, A) H\&E, 200x, B) EVG, 200x.
Figure 3: Ozone group: endothelium nearly regular and uniform, A) H\&E, 200x, B) EVG, 200x. 
Table I: Vascular Wall Thickness and Lumen Diameter of the Groups

\begin{tabular}{|c|c|c|c|c|c|}
\hline & $\begin{array}{c}{ }^{1} \text { Control } \\
(n=8)\end{array}$ & ${ }^{2}$ Vasospasm $(n=8)$ & $\begin{array}{c}\text { Vasospasm + } \\
\text { Ozone }(n=8)\end{array}$ & ${ }^{\mathrm{a}} \mathbf{p}$ & $\begin{array}{c}\text { pair-wise } \\
\text { comparison; }{ }^{b} p\end{array}$ \\
\hline \multicolumn{6}{|l|}{ Wall thickness } \\
\hline Min-Max (Median) & $\begin{array}{c}240.05-341.44 \\
(314.26)\end{array}$ & $\begin{array}{c}338.86-486.82 \\
(382.58)\end{array}$ & $\begin{array}{c}200.94-391.4 \\
(281.57)\end{array}$ & \multirow{2}{*}{$0.003^{\star *}$} & \multirow{2}{*}{$\begin{array}{c}{ }^{1-2} p: 0.002^{* *} \\
{ }_{1-3} p: 0.600 \\
{ }^{2-3} p: 0.009^{* *}\end{array}$} \\
\hline$M e d \pm S D$ & $300.90 \pm 40.17$ & $384.41 \pm 49.13$ & $289.23 \pm 65.98$ & & \\
\hline Min-Max (Median) & $\begin{array}{c}241.35-526.16 \\
(369.41)\end{array}$ & $\begin{array}{c}88.91-117.15 \\
(109.42)\end{array}$ & $\begin{array}{c}104.13-291.39 \\
(175.33)\end{array}$ & \multirow{2}{*}{$0.001^{\star *}$} & \multirow{2}{*}{$\begin{array}{l}{ }^{1-2} p: 0.001^{* *} \\
{ }^{1-3} p: 0.001^{* *} \\
{ }^{2-3} p: 0.006^{* *}\end{array}$} \\
\hline$M e d \pm S D$ & $377.51 \pm 91.73$ & $106.79 \pm 9.69$ & $182.59 \pm 58.48$ & & \\
\hline
\end{tabular}

${ }^{a}$ Kruskal-Wallis test, ${ }^{b}$ Mann-Whitney $U$ test, ${ }^{*} p<0.01$.

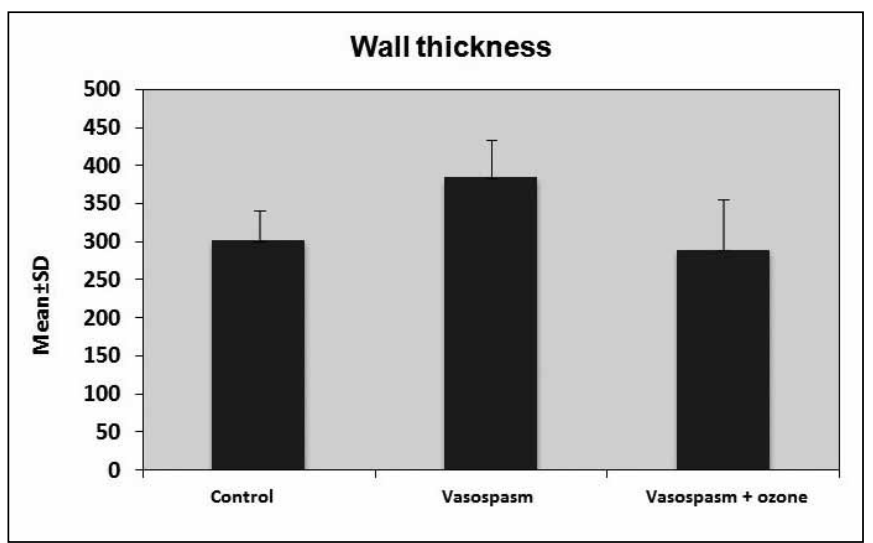

Figure 4: Comparison of mean vessel wall thicknesses.

The mean lumen diameter was also statistically significantly lower in the vasospasm ozone group than the control group $(p=0.001 ; p<0.01)$.

\section{DISCUSSION}

Despite the enormous advances in neuroscience, there is no definitive treatment of cerebral vasospasm following $\mathrm{SAH}$. Many pathological pathways are suggested to be responsible for the post hemorrhagic vasospasm that can cause morbidity and mortality $(14,28)$. It has been well demonstrated that reactive oxygen species play a key role in the pathophysiology of cerebral vasospasm and subsequent cerebral ischemia $(21,24)$. Free radical-mediated injuries $(11,28)$ and inflammation $(1,14)$ are among the important theories for the pathogenesis of vasospasm. Ozone, a gas composed of three atoms, is the third most potent oxidant after fluorine and persulfate (5). Ozone has been used medically for its strong effects on inflammation and oxidation $(2,3)$.

It was reported that controlled ozone administration promotes an oxidative preconditioning or adaptation to oxidative stress (9). Age-related macular degeneration, ischemic and infectious diseases and wound healing disorders are among the diseases where ozone therapy has proven its benefit

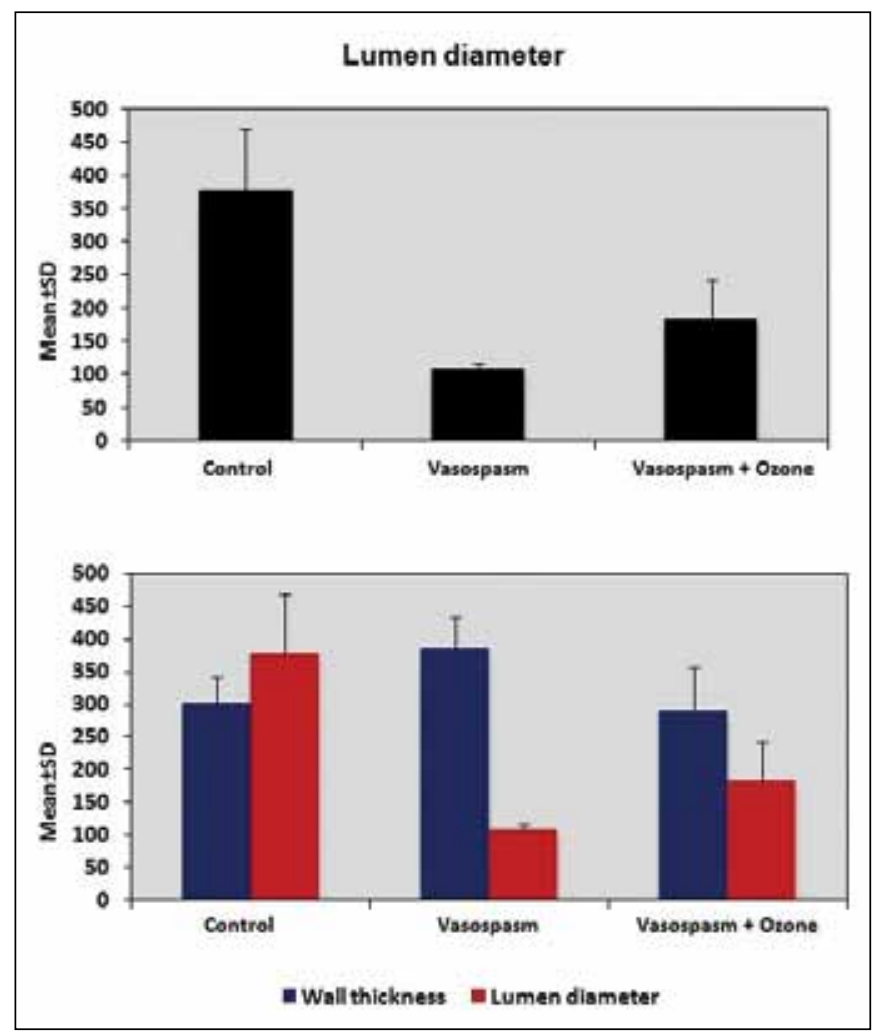

Figure 5: Comparison of vascular lumen areas.

(4). It has been shown that ozone preconditioning protects against the cellular damage by free radicals (18). In an animal study, Frosini et al. (10) reported that $\mathrm{O}_{3}$ in selective concentrations may have a role in inducing ischemic damage in brain tissue after a stroke. El-Sawalhi et al. (9) reported that ozone administration by rectal insufflations reduced lipid and protein oxidation in the hippocampus and heart tissues and normalized the glutathione peroxidase activity in heart tissue.

Souza et al. (27) found that ozone therapy has possible benefit in attenuating the inflammatory response. Chen et al. (7) showed that ozone oxidative preconditioning inhibited 
inflammation and apoptosis in a rat model of renal ischemia/ reperfusion injury. Wang et al. (30) pointed out that ozone may exert its protective effects by a mechanism involving modulation of the transforming growth factor- $\beta 1 / \mathrm{Smad} 7$ pathway in their study investigating ozone therapy and renal fibrosis.

While ozone has side effects and can irritate the respiratory system in humans and animals, the use of ozone has mostly been experimental (27). Ozone contact with the eyes and lungs should be avoided as these organs are very sensitive to ozone and have minimal antioxidant and neutralizing capabilities (5). Inhalation of ozone may cause acute arterial vasoconstriction in humans (6). $\mathrm{O}_{3}$ has two roles: it can cause oxidative damage in high concentrations and it can achieve a therapeutic effect with low concentrations $(19,25)$. In this study, $\mathrm{O}_{3}$ doses were used at low concentrations such as $4 \mathrm{~mL}$ of $20 \mu / \mathrm{mL}$; it has been used safely in doses of $20 \mathrm{ml} / \mathrm{kg}$ (27), $25 \mu / \mathrm{mL}$ (25) and $80 \mu / \mathrm{mL}(10)$ in previous studies.

Animal models investigating chronic vasospasm are well known (22). Okada et al. (23) was the first to describe the femoral artery model to induce experimental chronic vasospasm. They showed temporal evolution of arterial narrowing and morphological changes observed in the rat femoral artery were analogous to the time course of vasospasm in human and experimental SAH. There are many papers using this method for experimental vasospasm research $(11,12,14)$. To our knowledge, there is no published paper on whether ozone has any effect on rat femoral artery vasospasm.

In this study, data analysis of histopathological and morphometric measurements with imaging analysis for vasospasm supported the notion that ozone therapy may be useful in treating post hemorrhagic vasospasm. Histological findings showed that ozone partially prevented endothelial disruption in the vasospasm group. Normal internal elastic laminae were shown. There was no hemorrhage or vacuolization in the tunica media. The measurements of wall thickness and lumen diameters revealed that ozone played a significant positive role in resolving vascular vasospasm and enlarging the vascular lumen in rat femoral arteries.

\section{CONCLUSION}

The results of this study indicate a promising therapeutic effect of ozone. This effect may be a result of the addition of antioxidant and anti-inflammatory features of the ozone molecule mentioned above.

\section{- REFERENCES}

1. Baggott CD, Aagaard-Kienitz B: Cerebral vasospasm. Neurosurg Clin N Am 25(3):497-528, 2014

2. Bocci V: A new medical drug. $2^{\text {nd }}$ ed. Dordrecht: Springer, 2011

3. Bocci V, Zanardi I, Travagli V: Ozone: A new therapeutic agent in vascular diseases. Am J Cardiovasc Drugs 11(2):73-82, 2011

4. Bocci V: The case for oxygen-ozonet herapy. Br J Biomed Sci 64(1):44-49, 2007

5. Bocci VA: Scientific and medical aspects of ozone therapy. State of the art. Arch Med Res 37(4):425-435, 2006
6. Brook RD, Brook JR, Urch B, Vincent R, Rajagopalan S, Silverman $\mathrm{F}$ : Inhalation of fine particulate air pollution and ozone causes acute arterial vasoconstriction in healthy adults. Circulation 105(13):1534-1536, 2002

7. Chen H, Xing B, Liu X, Zhan B, Zhou J, Zhu H, Chen Z: Ozone oxidative preconditioning inhibits inflammation and apoptosis in a rat model of renal ischemia/reperfusion injury. Eur $\mathrm{J}$ Pharmacol 581(3):306-314, 2008

8. Curry TB, Bacon DR, Rho RH: The history of subcutaneous oxygen therapy. J Clin Anesth 18: 388-395, 2006

9. El-Sawalhi MM, Darwish HA, Mausouf MN, Shaheen AA: Modulation of age-related changes in oxidative stress markers and energy status in the rat heart and hippocampus: A significant role for ozone therapy. Cell Biochem Funct 31(6):518-525, 2013

10. Frosini M, Contartese A, Zanardi I, Travagli V, Bocci V: Selective ozone concentrations may reduce the ischemic damage after a stroke. Free Radic Res 46(5):612-618, 2012

11. Gumus E, Adilay U, Gunaldi O, Bayindir C, Kazanci B, Guclu B: The effect of copper on vasospastic femoral artery in rats. Turk Neurosurg 24(1):25-29, 2014

12. Gunaldi $O$, Tuğcu B, Cöllüoğlu B, Güçlü DG, Tanriverdi $O$, Akdemir $\mathrm{H}$, Bayindir $\mathrm{C}$ : Morphometric analysis of the influence of selenium over vasospastic femoral artery in rats. Acta Neurochir (Wien) 152(5):855-860, 2010

13. Guven A, Gundogdu G, Sadir S, Topal T, Erdogan E, Korkmaz A, Surer I, Ozturk H: The efficacy of ozone therapy in experimental caustic esophageal burn. J Pediatr Surg 43(9):1679-1684, 2008

14. Hakan T, Berkman MZ, Ersoy T, Karataş I, San T, Arbak S: Antiinflammatory effect of meloxicam on experimental vasospasm in the rat femoral artery. J Clin Neurosci 15(1):55-59, 2008

15. İnal M, Dokumacıoğlu A, Ozcelik E, Uçar O: The effects of ozone therapy and Coenzyme Q10 combination on oxidative stress markers in healthy subjects. Ir J Med Sci 180(3):703-707, 2011

16. Kamezaki T, Yanaka K, Nagase S, Fujita K, Kato N, Nose T: Increased levels of lipid peroxides as predictive of symptomatic vasospasm and poor outcome after aneurysmal subarachnoid hemorrhage. J Neurosurg 97(6):1302-1305, 2002

17. Kanamaru K, Suzuki H, Taki W: Risk factors for vasospasminduced cerebral infarct when both clipping and coiling are equally available. Acta Neurochir Suppl 120:291-295, 2015

18. León OS, Menéndez S, Merino N, Castillo R, Sam S, Pérez L, Cruz E, Bocci V: Ozone oxidative preconditioning: A protection against cellular damage by free radicals. Mediators Inflamm 7(4):289-294, 1998

19. Lin Q, Chen H, Lu C, Wang B, Zhang $Y$, He X, Yu B: Effects of ozone on sciatic nerve in rat. Interv Neuroradiol 17(3):281-285, 2011

20. Macdonald RL, Weir BK, Runzer TD, Grace MG: Malondialdehyde, glutathione peroxidase, and superoxide dismutase in cerebrospinal fluid during cerebral vasospasm in monkeys. Can J Neurol Sci 19(3):326-332,1992

21. Matsuda N, Ohkuma H, Naraoka M, Munakata A, Shimamura $\mathrm{N}$, Asano K: Role of oxidized LDL and lectin-like oxidized LDL receptor-1 in cerebral vasospasm after subarachnoid hemorrhage. J Neurosurg 121(3):621-630, 2014

22. Megyesi JF, Vollrath B, Cook DA, Findlay JM: In vivo animal models of cerebral vasospasm: A review. Neurosurgery 46(2):448461, 2000

23. Okada T, Harada T, Bark DH, Mayberg MR: A rat femoral artery model for vasospasm. Neurosurgery 27:349-356, 1990 
24. Pyne-Geithman GJ, Caudell DN, Prakash P, Clark JF: Glutathione peroxidase and subarachnoid hemorrhage: Implications for the role of oxidative stress in cerebral vasospasm. Neurol Res 31(2):195-199, 2009

25. Re L, Mawsouf MN, Menéndez S, León OS, Sánchez GM, Hernández F: Ozone therapy: Clinical and basic evidence of its therapeutic potential. Arch Med Res 39(1):17-26, 2008

26. Rodríguez ZZ, Guanche D, Alvarez RG, Rosales FH, Alonso Y, Schulz S: Preconditioning with ozone/oxygen mixture induces reversion of some indicators of oxidative stress and prevents organic damage in rats with fecal peritonitis. Inflamm Res 58(7):371-375, 2009

27. Souza YM, Fontes B, Martins JO, Sannomiya P, Brito GS, Younes $\mathrm{RN}$, Rasslan S: Evaluation of the effects of ozone therapy in the treatment of intra-abdominal infection in rats. Clinics (Sao Paulo) 65(2):195-202, 2010
28. Ton T, Ovalioglu AO, Ton O, Bilge T, Kiris T: Dose dependent morphological effects of alphalipoic acid on vasospastic femoral artery in rats. Turk Neurosurg 23(2):155-160, 2013

29. Uekusa H, Miyazaki C, Kondo K, Harada N, Nomoto J, Sugo N, Nemoto M: Hydroperoxide in internal jugular venous blood reflects occurrence of subarachnoid hemorrhage-induced delayed cerebral vasospasm. J Stroke Cerebrovasc Dis 23(9):2217-2224, 2014

30. Wang L, Chen H, Liu XH, Chen ZY, Weng XD, Quu T, Liu L, Zhu HC: Ozone oxidative preconditioning inhibits renal fibrosis induced by ischemia and reperfusion injury in rats. Exp Ther Med 8(6):17641768,2014 